\title{
The Empirical Analysis to Enhance Taiwanese Satisfaction in Buying Vietnam Coffee
}

\author{
Thi Nham Le, Chia Nan Wang, Ying Fang Huang \\ Department of Industrial Engineering and Management, National Kaohsiung University of Applied, Taiwan
}

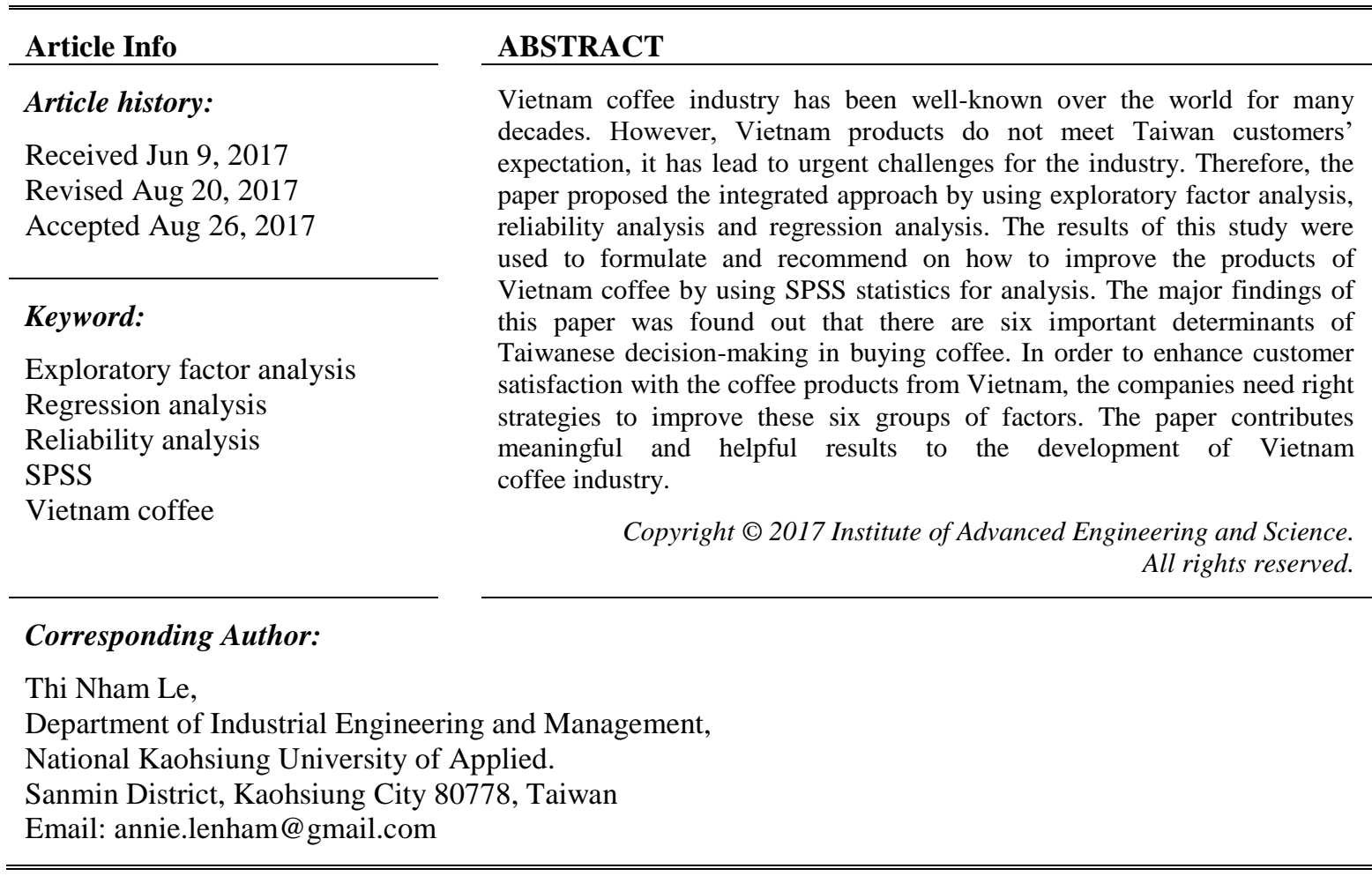

\section{INTRODUCTION}

Coffee production has been major economic industry for Vietnam since the early of 20th century, coffee is the nation's second-largest agricultural export products in term of value, after rice. Therefore, the industry has been attracted by many researchers and reporters over the world [1-2]. According to Global Trade Atlas (GTA), Vietnam exported 10.95 million $60-\mathrm{kg}$ bags in the first six months of period from octorber 2014 to March 2015 to 82 countries and territories around the world [3]. Vietnam is the second largest coffee exporter in the world with famous trademarks; one of them is Trung Nguyen coffee [4-6]. According to figure 1, Taiwan is the fix largest importer of Vietnamese coffee. It indicates that Taiwan has been a potential market for Vietnam coffee manufacturers.

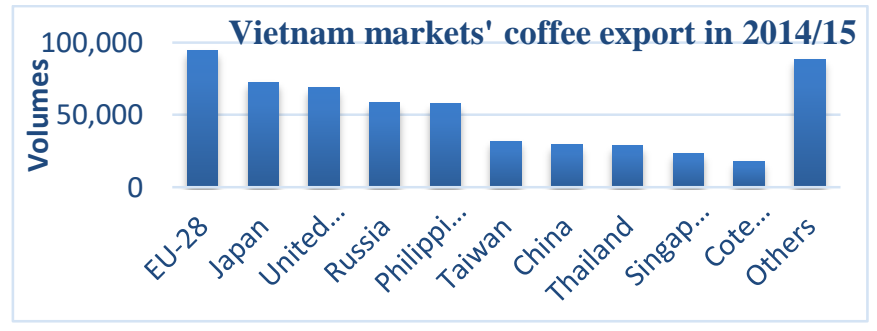

Figure 1. Vietnam Key Market's Coffee Export In October 2014 to March 2015 
The rapid expansion of production is a strong point of Vietnam coffee industry but leads to some imbalances that need to be urgently taken into account, especially when Vietnam coffee industry penetrated into new market such as Taiwan [7]. Taiwanese people have been used to drink tea and coffee brands from the US and Japan. Taiwan current market situation is high competitive, it is rather difficult for Vietnam coffee producers. Therefore, in order to establish a good foundation and develop Vietnam coffee products in Taiwan, the industry needs to improve its products based on local people's needs. The coffee development program are still carried out, it is necessary to work out an adjustment for long-term of sustainable development in order to focus on Taiwan's potential segment.

In order to improve product quality to foreign market demands, the technique of coffee processing and designing should be improved. However, the strategy is to meet customers' need has been never easy. Therefore, the innovative analysis is applied in this paper by using SPSS statistics. It combined three steps of methodologies, they are Exploratory Factor Analysis (EFA), Reliability Analysis, and Regression Analysis. Exploratory factor analysis was used to find out the determinants of buying Vietnam coffee in Taiwan market. The purpose of reliability analysis is to assess the degree of consistency among multiple measurements of a variable. Regression analysis is used to find out the importance of each elements, which influence to the satisfaction of customers who have experienced in enjoying Vietnam coffee.

In this study, the authors contribute to development of Vietnam coffee industry in Taiwan market. The study aims to evaluate customers' satisfaction by applying practical analysis. It is valued insights for Vietnamese managers and researchers to understand what customers really expect the qualitative products and services from original manufacturers. The findings of main determinants help Vietnam coffee companies make right market strategies to enhance decision-making of Taiwan people in buying their favorite coffee.

\section{RESEARCH METHOD}

In this paper, questionnaires are designed based on the famous book "Questionnaire design, interviewing and attitude measurement" by Oppenheim in 1992 [8]. The paper made survey in Taiwan, among the total 200 people were interviewed and recorded, there are 129 people who have been drinking coffee for over 3 years, accounting for $64.5 \%$ of the total observations. $78.5 \%$ of the respondents have enjoyed coffee for more than 1 year. This indicates that the people in this survey have enough experience to choose their favorite coffee and respondents' feedback are useful for this research.

This section describes data analysis methods includes 27 statements. These statements are used to appreciate the importance level of factors that is affecting customer decision and evaluating the satisfaction customer level of factors in using Vietnam coffee. This part of the questionnaire use a five point bipolar scale are very unimportant, unimportant, normal, important, very important, and they respectively have convention as (1), (2), (3), (4), and (5) [9-11]. Content of 27 statements relate to price, promotion, package, color, taste, smell, storage, alcohol content, brand, etc. In order to analyze the data from the survey, the first necessary step is encoding system of the responses. The valid responses are encoded as conventions in Table 1.

\subsection{Exploratory Factor Analysis}

Factor analysis is an analysis tools to find the structure of the correlations among a large number of variables by defining set of variables which are highly interrelated, called factors [12]. In this research, Exploratory Factor Analysis (EFA) approach is applied to find out the determinants of the decision-making of Taiwanese customers in buying coffee (Williams et al, 2010) [13]. Therefore, EFA approach aims to identify representative variables from a larger set of variables for use in subsequent multivariate analysis. KMO and Bartlett's Test of Sphericity is a measure of sampling adequacy that is recommended to check the case to variable ratio for the analysis being conducted. KMO \& Bartlett's test play an important role for accepting the sample adequacy. For Factor Analysis to be recommended suitable, KMO ranges from 0 to 1 and the Bartlett's Test of Sphericity must be less than 0.05 [14-15]. The application of EFA approach to reduce the number of variables from a larger set is refered as data reduction.

The elements from $\mathrm{C} 1$ to $\mathrm{C} 27$ are analyzed by EFA approach to find out the six determinants of decision-making of Taiwanese customers in buying their favorite coffee. The results of outputs from SPSS statistics, the KMO value of this analysis is 0.816 with the significance of Bartlett's Test of Sphericity is 0.000 . Thus, EFA model in this study is appropriate. Finally, six components of 27 values are factors of color and smell, package, concentration, brand, sugar and milk, contact information, they are designated as order as F1 to F6. The six factors are now to be tested for their reliability with Cronbach's alpha coefficient. 
Table 1. Encoded System Based on Questionnaires

\begin{tabular}{|c|c|c|c|}
\hline No. & Statement & $\begin{array}{c}\text { Importance } \\
\text { level }\end{array}$ & $\begin{array}{c}\text { Satisfaction } \\
\text { level }\end{array}$ \\
\hline 1 & Reasonable price & $\mathrm{C} 1$ & D1 \\
\hline 2 & Promotion programs of company & $\mathrm{C} 2$ & D2 \\
\hline 3 & Presentable packaging & $\mathrm{C} 3$ & D3 \\
\hline 4 & Languages printed on the packet of products & $\mathrm{C} 4$ & D4 \\
\hline 5 & Product packaging is easy to tear & $\mathrm{C} 5$ & D5 \\
\hline 6 & The net weight of coffee in one packet & C6 & D6 \\
\hline 7 & High concentrations of coffee in packet & $\mathrm{C} 7$ & D7 \\
\hline 8 & Expired time of product & $\mathrm{C} 8$ & D8 \\
\hline 9 & Color of coffee before making coffee & C9 & D9 \\
\hline 10 & Color of coffee after making coffee & $\mathrm{C} 10$ & D10 \\
\hline 11 & Good smell of the coffee before making & $\mathrm{C} 11$ & D11 \\
\hline 12 & Good smell of the coffee after making & $\mathrm{C} 12$ & D12 \\
\hline 13 & The special and attractive flavor & $\mathrm{C} 13$ & D13 \\
\hline 14 & The time of keeping smell after making & $\mathrm{C} 14$ & D14 \\
\hline 15 & The coffee viscosity after making & $\mathrm{C} 15$ & D15 \\
\hline 16 & Bitter taste of coffee & $\mathrm{C} 16$ & D16 \\
\hline 17 & Sour taste of coffee & $\mathrm{C} 17$ & D17 \\
\hline 18 & High level of sugar in coffee & $\mathrm{C} 18$ & D18 \\
\hline 19 & Milk concentration in coffee & $\mathrm{C} 19$ & D19 \\
\hline 20 & The alertness after drinking coffee & $\mathrm{C} 20$ & D20 \\
\hline 21 & Recognizable brand & $\mathrm{C} 21$ & D21 \\
\hline 22 & Trusted brand & $\mathrm{C} 22$ & D22 \\
\hline 23 & Clear contact information of the manufacturer & $\mathrm{C} 23$ & D23 \\
\hline 24 & Different types of coffee from the same brand & $\mathrm{C} 24$ & D24 \\
\hline 25 & The widespread advertisement & $\mathrm{C} 25$ & D25 \\
\hline 26 & The ease in storage & $\mathrm{C} 26$ & D26 \\
\hline 27 & The ease in use & $\mathrm{C} 27$ & D27 \\
\hline
\end{tabular}

\subsection{Reliability Analysis}

The purpose of reliability analysis is to assess the degree of consistency among multiple measurements of a variable. Chronbach's alpha is designed as a measure of internal consistency. Cronbach's Alpha is most appropriately used when the items measure different substantive areas within a single construct (Schmitt, 1996) [16]. Alpha is measured on the same scale as a correlation coefficient and typically varies between 0 and 1 .

In reliability analysis, when a factor is considered consistently, Cronbach's Alpha is used to create a summary statistics for the factors in the "importance level" and relevant variables in the "satisfaction level". Then based on the minimum, mean, and maximum values of each factor. Cronbach's Alpha is compared together to know whether Vietnam coffee has satisfied its customers to what extent. In this paper, the Cronbach's alpha coefficient while running SPSS statistics is 0.695 in average, this indicates that all items have strongly high internal consistency. This help to find out the gap between the customers expectation on their using coffee and the actual performance of Vietnam coffee companies based on their judgments. As per the above reliability analysis, all of the six factors extracted are reliable for further analysis. Based on the values of mean of the importance level, the six factors are ranked as in Table 2.

Table 2. Rank the Importance of Six Factors in the Decision-Making

\begin{tabular}{cccccc}
\hline Rank\# & Factor & Mean & Min & Max \\
\hline 1 & F3 & Smell, special flavor, high concentrations, expiry & 4.034 & 3.905 & 4.220 \\
2 & F5 & $\begin{array}{c}\text { Milk concentrations, sugar level } \\
\text { Languages printed, promotion programs, }\end{array}$ & 3.893 & 3.855 & 3.930 \\
3 & F2 & packaging easy tear, presentable packaging & 3.846 & 3.640 & 4.010 \\
4 & F4 & Brand, advertisements & 3.760 & 3.588 & 4.045 \\
5 & F1 & Time of keeping smell, taste, color & 3.519 & 3.345 & 3.685 \\
6 & F6 & Various types, contact information & 3.420 & 3.407 & 3.422 \\
\hline
\end{tabular}

Based on the above Table, consumers in Taiwan pay most attention to five characteristics of coffee, including: smell, special flavor, high concentrations of coffee, expiry time and net weight per package. This is the first determinant of decision-making of Taiwanese in buying their favorite coffee. The second determinant is the milk concentration and sugar level in the package. Other four determinants are also very important. Any company doing business in coffee industry should take all of these six factors into their 
consideration to create proper actions to meet their customers' expectations. With the six determinants, the customers' expectations on each factor are already shown under the mean, minimum and maximum values summarized in Table 2. Based on the items in these factors, the customer satisfaction level to Vietnam coffee is accordingly calculated. Table 3 shows the corresponsive items between importance level and the satisfaction level.

From data of Table 3, the mean, minimum and maximum values of the six factors in the satisfaction level are calculated by the reliability analysis and shown in Table 4. From comparing the Figures in Table 4, it can be seen that Vietnam coffee has well performed in F1 and F6. However, the products do not meet the customers' expectations in remaining four factors, including F2, F3, F4 and F5. Table 6 demonstrates the details of the satisfaction level on each factor compared to relevant importance level. It indicates each item in the above factors of both satisfaction level and important level, which values Vietnam coffee companies should put more efforts in order to be successful in its development. The mean of each item calculated here is done with the simple average method which is different from the above means calculated under reliability analysis.

Table 3. Corresponsive Items Between Important Level And Satisfaction Level

\begin{tabular}{lll}
\hline Factor & $\begin{array}{l}\text { Important } \\
\text { Level }\end{array}$ & $\begin{array}{l}\text { Satisfaction } \\
\text { Level }\end{array}$ \\
\hline \multirow{4}{*}{ F1 } & C14 & D14 \\
& C15 & D15 \\
& C16 & D16 \\
& C17 & D17 \\
& C10 & D10 \\
F2 & C4 & D4 \\
& C2 & D2 \\
& C5 & D5 \\
& C3 & D3 \\
F3 & C12 & D12 \\
& C13 & D13 \\
& C7 & D7 \\
& C8 & D8 \\
F4 & C6 & D6 \\
& C21 & D21 \\
F5 & C22 & D22 \\
& C25 & D25 \\
F6 & C19 & D19 \\
& C18 & D18 \\
\hline \multirow{4}{*}{ C24 } & D24 \\
& C23 & D23 \\
\hline
\end{tabular}

Table 4. The Calculated Values Of Six Factors in the

\begin{tabular}{cccc}
\multicolumn{4}{c}{ Satisfaction Level } \\
\hline Factor & Mean & Min & Max \\
\hline F1 & 3.680 & 3.547 & 3.761 \\
F2 & 3.296 & 3.162 & 3.478 \\
F3 & 3.055 & 2.978 & 3.209 \\
F4 & 2.844 & 2.664 & 2.955 \\
F5 & 3.795 & 3.778 & 3.812 \\
F6 & 3.662 & 3.607 & 3.718 \\
\hline
\end{tabular}

Table 5. Satisfaction level on each factor

\begin{tabular}{cccc}
\hline Factor & $\begin{array}{c}\text { Satisfaction } \\
\text { Mean }\end{array}$ & $\begin{array}{c}\text { Important } \\
\text { Mean }\end{array}$ & $\begin{array}{c}\text { Satisfaction } \\
\text { radio }\end{array}$ \\
\hline F1 & 3.680 & 3.519 & $104.6 \%$ \\
F2 & 3.296 & 3.846 & $85.7 \%$ \\
F3 & 3.055 & 4.034 & $75.7 \%$ \\
F4 & 2.844 & 3.760 & $75.6 \%$ \\
F5 & 3.795 & 3.893 & $97.5 \%$ \\
F6 & 3.662 & 3.420 & $107.1 \%$ \\
\hline
\end{tabular}

Table 6. Satisfaction Level on Each Item of Six Factors Arranged to Important Mean

\begin{tabular}{cllccc}
\hline $\begin{array}{c}\text { Factor } \\
\text { Rank }\end{array}$ & \multirow{2}{*}{ Item } & \multicolumn{1}{c}{ Content } & $\begin{array}{c}\text { Importance } \\
\text { Mean }\end{array}$ & $\begin{array}{c}\text { Satisfaction } \\
\text { Mean }\end{array}$ & $\begin{array}{c}\text { Satisfaction and } \\
\text { Importance ratio }\end{array}$ \\
\hline F3 (1st) & 12 & Smell after making & 4.22 & 3.04 & $72.0 \%$ \\
F3 (1st) & 13 & Special flavor & 4.17 & 3.09 & $74.1 \%$ \\
F2 (3rd) & 5 & Packaging easy tear & 4.12 & 3.48 & $84.5 \%$ \\
F4 (4th) & 22 & Trusted brand & 4.04 & 2.97 & $3.5 \%$ \\
F3 (1st) & 8 & Expiry time & 3.97 & 2.95 & $74.3 \%$ \\
F5 (2nd) & 19 & Milk concentration & 3.93 & 3.77 & $95.9 \%$ \\
F2 (3rd) & 3 & Presentable packaging & 3.92 & 3.34 & $85.2 \%$ \\
F3 (1st) & 7 & High concentrations & 3.91 & 3.12 & $79.8 \%$ \\
3 (1st) & 6 & Net weight & 3.91 & 2.97 & $76.0 \%$ \\
F5 (2nd) & 18 & Sugar level & 3.86 & 3.81 & $98.7 \%$ \\
F1 (5th) & 14 & Keeping smell time & 3.76 & 4.01 & $106.6 \%$ \\
F1 (5th) & 10 & Color after making & 3.74 & 3.84 & $102.4 \%$ \\
F2 (3rd) & 2 & Promotion programs & 3.70 & 3.20 & $86.5 \%$ \\
F2 (3rd) & 4 & Languages printed & 3.69 & 3.16 & $85.6 \%$ \\
F1 (5th) & 15 & Coffee viscosity & 3.68 & 3.81 & $103.4 \%$ \\
F1 (5th) & 16 & Bitter taste & 3.67 & 3.94 & $107.3 \%$ \\
F4 (4th) & 21 & Recognizable brand & 3.65 & 2.85 & $78.1 \%$ \\
F4 (4th) & 25 & Widespread advertisement & 3.59 & 2.69 & $74.9 \%$ \\
F1 (5th) & 17 & Sour taste & 3.55 & 3.64 & $102.6 \%$ \\
F6 (6th) & 23 & Contact information & 3.43 & 3.56 & $103.8 \%$ \\
F6 (6th) & 24 & Many types & 3.40 & 3.77 & $110.9 \%$ \\
\hline & & & & &
\end{tabular}


Table 6 also shows that Taiwanese people are paying most attention to the smell of the coffee after making, also its special flavor, the ease of tearing the package and the brand. All of these elements have the mean values of more than 4 points in the scale of 5 points and they are in 3 factors that are top ranked in the six determinants found. In order to win this market, Vietnam must be aware of its coffee performance as per the evaluation of each specific element shown in Table 6.

\subsection{Regression Analysis}

After using reliability analysis method to compare elements with others and to find out the role of each element in creating satisfied of customers who have experience in enjoying Vietnam coffee. Regression Analysis method is used to analyze these elements to determine the state of customer's satisfaction for remaining advantages and improving disadvantages of these elements for Vietnam coffee's development.

In statistics, regression analysis is a statistical method to know the relationships between variables. Regression analysis includes many techniques for modeling and analyzing some variables, focusing on the relationship between a dependent variable and one or more independent variables. Specifically, regression analysis helps researcher understand how the typical value of the dependent variable changes when any one of the independent variables is changed, while the other independent variables are held fixed (Hair et al, 2010) [17].

The formulation of regression analysis is shown as the following:

$$
y=a_{0}+a_{1} x_{1}+a_{2} x_{2}+\ldots+a_{n} x_{n}+\varepsilon
$$

In here: $\mathrm{a}_{0}$ :

$$
\begin{array}{ll}
\mathrm{a}_{1}, \mathrm{a}_{2} \ldots \mathrm{a}_{\mathrm{n}}: & \text { Regression coefficients. } \\
\mathrm{x}_{1}, \mathrm{x}_{2}, \ldots, \mathrm{x}_{\mathrm{n}}: & \text { Independent variables. } \\
\mathrm{y}: & \text { Dependent variable } \\
\mathcal{E}: & \text { Error }
\end{array}
$$

The method of least squares is a standard approach to the approximate solution of over-determined systems or inexactly specified systems. "Least squares" means that the overall solution minimizes the sum of the squares of the errors made in the results of every single equation. This method defines the estimate of these parameters and defined as following formula:

$$
\varepsilon_{i}=y_{i}-\hat{y}_{i}=y_{i}-a_{0}-a_{1} x_{1 i}-\ldots-a_{n} x_{n i}(i=1,2,3, \ldots m)
$$

And the OLS method is shown as follow:

$$
\sum_{i=1}^{m} \varepsilon_{i}^{2} \rightarrow \min
$$

Now the parameters $a_{0}, a_{1}, a_{2} \ldots a_{n}$ in the regression models are easily obtained because of the great advances in computer technology and software. After determining the parameters, it is necessary to test the significance of the overall model and each regression coefficients. The significance of the overall model is determined by comparing the significance of F-statistic (F-sig.) by Anova statistic [18-19]. The given significance level is usually accepted at 0.05 (or 5\%).

In this section, another analysis called regression analysis is used to evaluate the role of each factor to the overall satisfaction level to Vietnam coffee. In regression analysis, the overall satisfaction level (coded as variable E) is the dependent variable and the six factors are independent variables. The analysis results are as in Table 7.

Table 6 also shows that Taiwanese people are paying most attention to the smell of the coffee after making, also its special flavor, the ease of tearing the package and the brand. All of these elements have the mean values of more than 4 points in the scale of 5 points and they are in 3 factors that are top ranked in the six determinants found. In order to win this market, Vietnam must be aware of its coffee performance as per the evaluation of each specific element shown in Table 6 . 


\subsection{Regression Analysis}

After using reliability analysis method to compare elements with others and to find out the role of each element in creating satisfied of customers who have experience in enjoying Vietnam coffee. Regression Analysis method is used to analyze these elements to determine the state of customer's satisfaction for remaining advantages and improving disadvantages of these elements for Vietnam coffee's development.

In statistics, regression analysis is a statistical method to know the relationships between variables. Regression analysis includes many techniques for modeling and analyzing some variables, focusing on the relationship between a dependent variable and one or more independent variables. Specifically, regression analysis helps researcher understand how the typical value of the dependent variable changes when any one of the independent variables is changed, while the other independent variables are held fixed (Hair et al, 2010) [17].

The formulation of regression analysis is shown as the following:

$$
y=a_{0}+a_{1} x_{1}+a_{2} x_{2}+\ldots+a_{n} x_{n}+\varepsilon
$$

In here: $\mathrm{a}_{0}$ :

$$
\begin{array}{ll}
\mathrm{a}_{1}, \mathrm{a}_{2} \ldots \mathrm{a}_{\mathrm{n}}: & \text { Regression coefficients. } \\
\mathrm{x}_{1}, \mathrm{x}_{2}, \ldots, \mathrm{x}_{\mathrm{n}}: & \text { Independent variables. } \\
\mathrm{y}: & \text { Dependent variable } \\
\varepsilon: & \text { Error }
\end{array}
$$

The method of least squares is a standard approach to the approximate solution of over-determined systems or inexactly specified systems. "Least squares" means that the overall solution minimizes the sum of the squares of the errors made in the results of every single equation. This method defines the estimate of these parameters and defined as following formula:

$$
\varepsilon_{i}=y_{i}-\hat{y}_{i}=y_{i}-a_{0}-a_{1} x_{1 i}-\ldots-a_{n} x_{n i}(i=1,2,3, \ldots m)
$$

And the OLS method is shown as follow:

$$
\sum_{i=1}^{m} \varepsilon_{i}^{2} \rightarrow \min
$$

Now the parameters $a_{0}, a_{1}, a_{2} \ldots a_{n}$ in the regression models are easily obtained because of the great advances in computer technology and software.

After determining the parameters, it is necessary to test the significance of the overall model and each regression coefficients. The significance of the overall model is determined by comparing the significance of F-statistic (F-sig.) by Anova statistic [18-19]. The given significance level is usually accepted at 0.05 (or $5 \%$ ).

\begin{tabular}{|c|c|c|c|c|c|c|c|}
\hline \multirow[b]{2}{*}{ Model } & \multicolumn{2}{|c|}{$\begin{array}{c}\text { Unstandardized } \\
\text { Coefficients }\end{array}$} & \multirow{2}{*}{$\begin{array}{c}\begin{array}{c}\text { Standardized } \\
\text { Coefficients }\end{array} \\
\text { Beta }\end{array}$} & \multirow[b]{2}{*}{$t$} & \multirow[b]{2}{*}{ Sig. } & \multicolumn{2}{|c|}{$\begin{array}{c}\text { Collinearity } \\
\text { Statistics }\end{array}$} \\
\hline & $B$ & Std. Error & & & & Tolerance & VIF \\
\hline $1 \quad$ (Constant) & 3.781 & .033 & & 114.258 & .000 & & \\
\hline F1 & .131 & .057 & .242 & 2.311 & .023 & .346 & 2.893 \\
\hline $\mathrm{F} 2$ & .198 & .043 & .367 & 4.585 & .000 & .589 & 1.698 \\
\hline F3 & .104 & .051 & .193 & 2.049 & .043 & .427 & 2.343 \\
\hline $\mathrm{F} 4$ & .056 & .045 & .105 & 1.256 & .212 & .544 & 1.840 \\
\hline F5 & .040 & .046 & .074 & .875 & .384 & .521 & 1.918 \\
\hline F6 & -.010 & .050 & -.018 & -.197 & .845 & .446 & 2.242 \\
\hline
\end{tabular}

In this section, another analysis called regression analysis is used to evaluate the role of each factor to the overall satisfaction level to Vietnam coffee. In regression analysis, the overall satisfaction level (coded as variable $\mathrm{E}$ ) is the dependent variable and the six factors are independent variables. The analysis results are as in Table 7.

Table 7. Coefficients

Coefficients $^{a}$ 
From Table 7, it can be concluded that F1, F2 and F3 are statistically significant in this regression model. Anova analysis is conducted to test the model fit as in Table 7 which reconfirms that the model is fit to the actual phenomenon and good enough to use in this study.

According to Table 6, with the given significance of 5\%, F4, F5 and F6 are not considered statistically significant because their significance values are greater than the given one. Thus, these variables are one-by-one dropped out of the regression model. The final results from regression analysis are presented in Table 8.

Table 8. Anova Analysis

ANOVA $^{\mathrm{b}}$

\begin{tabular}{l|r|r|r|r|r|}
\hline Model & Sum of Squares & df & Mean Square & F & Sig. \\
\hline $1 \quad$ Regression & 19.442 & 3 & 6.481 & 51.221 & $.000^{2}$ \\
Residual & 14.170 & 112 & .127 & & \\
Total & 33.612 & 115 & & & \\
\hline
\end{tabular}
a. Predictors: (Constant), F3, F2, F1
b. Dependent Variable: E

F2 has the highest value of standardized coefficient "Beta", F1 comes next and F3 has the lowest. This indicates that F2 has the strongest impact on the overall satisfaction level of the customers; F1 comes second; F3 comes third; whereas, F4, F5 and F6 do not have any effect on the overall satisfaction level of the customers towards Vietnam coffee. There are 6 major determinants affecting the decision-making in buying coffee of customer. These 6 determinants are resulted from analysis surveyed data by SPSS statistics. These factors are very important in meeting customers' expectation. Therefore, in order to dominate Taiwan market, Vietnam coffee should put more attention to meet customers' satisfaction based on these factors.

\section{RESULTS AND DISCUSSIONS}

The findings of the main determinants will help those coffee exporters create good strategies for their long term development. However, enhancing the current satisfaction level of the customers always face with difficulties on severe competitive market. Therefore, it is an urgent requirement for Vietnam coffee industry to have proper solutions to enhance its customer satisfaction.

Further to the results in Table 7, there are three main factors affecting the overall satisfaction level of the customers of Vietnam coffee. They are listed in Table 9. Among the three factors, F2 has the strongest influence on the overall satisfaction, F1 and F3 come in second and third, respectively. Currently, Vietnam coffee has a very good performance in terms of time of keeping good smell, the viscosity, taste and color after making which are the elements of factor F1. Therefore, it is obviously that Vietnam coffee companies should take this factor F1 as its strength on the market; and in this section, some solutions are suggested to enhance the current satisfaction level on F2 and F3 only. Therefore, this section provides some valued solutions in order to improve Taiwanese people's satisfaction and expectation in using Vietnam coffee brands.

\subsection{Solutions for Enhancing the Satisfaction Level on F2}

Taiwanese customers are currently unhappy with the packaging of Vietnam coffee regarding language printed on the package, ease of tearing the package, ability to use the package for present as well as the promotion program offered by Vietnam coffee companies. These elements are all in factor F2. Based on the results in table 5, Vietnam coffee can only satisfy about $85 \%$ of the customer expectations.

However, the current package of Vietnam coffee is not highly evaluated because there are fifteen sachets in a soft paper box which is easily crushed under a light pressure. Hence, once it is crushed, the utter box is usually thrown away after the packs are picked out which results in a feeling of inconvenience to store the coffee- making the customer unhappy and dis-satisfied. In order to make Vietnam coffee tin package differ from those of its competitors, it is suggested that Vietnamese coffee companies should design special shapes and packaging materials, such as wood, bamboo, etc. This is the main reason why customers are satisfied only $85.2 \%$ of their expectations in terms of presentable packaging in Table 7.

In addition, the customers do not satisfy about the product package when using. The current package can only meet $85.7 \%$ of the expectations from the customers. It can be easily found that the cut-edge for tearing the sachets is small and hardly recognized. There are also some sachets that do not have the cut-edge 
on; therefore, customers find it inconvenient to tear the sachets to make the coffee. It is now strongly suggested that the cut-edge on each sachet should be in V-shape and the machines doing the cut-edge on each sachet are to be well monitored and controlled so that every sachet has a good cut-edge.

Moreover, In order to accelerate Vietnam coffee's development, it is necessary to offer special promotion programs by offerring some small gifts to regular customers on special occasions such as: National Independence Day of Taiwan, Mid-autumn festival, Lunar New Year, etc... are effective ways to improve their satisfaction and loyalty to the products and/or services. the sales and marketing department of Vietnam coffee companies should create proper marketing campaigns, select proper advertisement channels in Taiwan to make the coffee consumers in Taiwan in order to be aware of the presence of a good coffee from Vietnam. In Taiwan, there are different chains of supermarkets, such as Family Marts, Seven Eleventh, Carrefour, etc., which are extremely good channels to launch the campaigns besides the official advertisements on public media, such as newspapers and television channels.

Table 9. Three Factors Affecting the Overall Satisfaction

\begin{tabular}{lll}
\hline Factor & tem & Content \\
\hline & 4 & Keeping smell time \\
& 5 & Coffee viscosity \\
F1 & 6 & Bitter taste \\
& & Sour taste \\
& 7 & Color after making \\
& 0 & Languages printed \\
& & Promotion programs \\
F2 & & $\begin{array}{l}\text { Packaging easy tear } \\
\text { Presentable packaging } \\
\end{array}$ \\
& & Smell after making \\
& 2 & Special flavor \\
F3 & 3 & High concentrations \\
& & Expiry time \\
& & Net weight \\
\hline
\end{tabular}

\subsection{Solutions for enhancing the satisfaction level on F3}

Based on Table 2 and Table 5, it is clearly shown that customers are currently satisfied only $75.7 \%$ on their expectations in terms of the smell after making, special flavor, coffee concentrations, net weight and expiry time. The ratio of satisfaction level is over the importance level at $75.7 \%$, which is considered a serious problem to Vietnam coffee industry in this market.

Table 6 indicates that special smell and flavor are important factors in attracting not only the coffee users but also others who may haven't tried coffee before or currently cannot use coffee due to their health problems. Coffee smell should be particularly recognizable fragrant and distinguishable with the other products. The most remarkable value of the coffee smell and flavor is that they give users alertness, and euphoria. However, Vietnam coffee companies cannot offer a better flavor than its competitors currently existing in Taiwan, which makes them extremely dis-satisfied. Therefore, coffee companies should improve its unique smell and flavor which requires a special effort in researching and development.

As a result, customers are also dis-satisfied with Trung Nguyen coffee in term of expiry date. To solve this problem, Vietnam coffee companies should carefully discuss with the Taiwan agents not selling products that will be expired within the next two months. To do this, they should support the agents by replacing the old products with the new ones. When the customers are happy with the products and get used to Vietnam coffee taste, the sales will be boosted up so there would be no stock remained.

\subsection{Solutions to Meet Customer's expectations.}

Based on analysis results in previous sector, there are six important determinants of decisionmaking. Among these six determinants, Table 2, 4 and 6 clearly shows that factor F3 is the most important determinant. This means that customers pay the most attention to smell, special flavor, coffee concentrations, expiry time, and net weight of coffee in a package. Vietnam coffee companies should take these elements 
into serious consideration to improve their products to meet the customers' expectations. The second important determinant relates to milk concentration and sugar level (F5) which implies that the taste of the consumers in Taiwan is more biased to sweetened coffee.

Another important issue is that the consumers also pay a lot attention to the packaging of the product in making their buying-decisions. Specifically, they usually consider the following elements in terms of languages printed, promotion programs, packaging easy tear, and presentable packaging. In a severe competition on the market, an attractive package will reach the buyers' attention which makes the purchase probability increased.

\section{CONCLUSION}

The coffee industry is now getting fiercer competition, therefore most of companies are trying to find out what factors being affected customers' buying-decisions and how they are currently satisfied with their products on its services. Furthermore, there are six main determinants of buying a favorite coffee of people are found in this study. In this study, Trung Nguyen Company and other Vietnam coffee brands are now having some certain problems to be solved in terms of language printed on the package, ease of tearing the package, and promotion programs offered by Vietnam coffee brands, the smell after making the coffee, the flavor, coffee concentrations, net weight and expiry time. Those problems are to be seriously considered and settled to enhance the customer satisfaction level.

In our limitations of this research, the paper aims to help Vietnam coffee companies solve these problems, some possible solutions were suggested as valued insights to market researchers. These solutions are considered as immediate actions that can improve the customers current satisfaction level of Vietnam coffee in Taiwan. However, the completely intergrated performance needs a detailed reevaluation in term of different markets that can be applied to and more input data from respondents. Those disadvantages will be improved by the future directions and researches.

\section{REFERENCES}

[1] Luong QV, Tauer LW. A Real Options Analysis of Coffee Planting in Vietnam. Agricultural Economics. 2006; 35(1): 49-59.

[2] Dang TH, Shively G. Coffee Boom, Coffee Bust and Smallholder Response in Vietnam's Central Highlands. Review of Development Economics. 2008; 12(2): 312-326.

[3] Nguyen H, Ward M. Vietnam Coffee Annual. USDA Global Agricultural Information Network. VM5030. 2015.

[4] Tran TT. Vietnam's Coffee Industry. Ipsos Agricultural Research and Consulting. 2013.

[5] Ministry of Agricultural and Rural Development (MARD). Available online: http://www.mard.gov.vn/. Accessed on March $19^{\text {th }} 2016$.

[6] Do TTH. The Influence of Brand Awareness on the Relationship Between Perceived Quality and Customer Satisfaction of G7 Coffee in Vietnam. Master Thesis. Meiho University, Taiwan. 2010.

[7] Doan TN. Vietnam Coffee Industry. Proceeding of International Coffee Conference. London, UK. 2001.

[8] Oppenheim, A.N. Questionnaire Design, Interviewing and Attitude Measurement. London: Pinter Publishers. 1992

[9] Fowler, F. Improving survey questions. Design and evaluation. London: Sage. 1995.

[10] Schwarz N, Hippler H. Response Alternatives: the Impact of their Choice and Presentation Order. In: Biemer PP, Groves RM, Lyberg LE. Editors. Measurement Errors in Surveys. New York: Wiley- Interscience.1991:41-56.

[11] Schwarz N, Hippler H, Deutsch B, Strack F. Response Scales: Effects of Category Range on Reported Behavior and Comparative Judgments. Public Opinion Quarterly. 1985; 49(3): 388-95.

[12] Boduszek D. Exploratory Factor Analysis in SPSS. University of Huddersfield.

[13] Williams AP et all. Forest Responses to Increasing Aridity and Warmth in the Southwestern United States. Proceedings of the National Academy of Sciences. USA. 2010: 21289-21294.

[14] Kaiser HF. The Application of Electronic Computers to Factors Analysis. Educational and Psychological Measurement. 1960; 20: 141-151.

[15] Kaiser HF. An Index of Factorial Simplicity. Psychometrika. 1974; 39: 31-36.

[16] Schmitt N. Uses and Abuses of Coefficient Alpha. Psychological Assessment. 1996; 8: 350-353.

[17] Hair JJF, Black WC, Babin BJ, Anderson RE. Multivariate Data Analysis: a Global Perspective. Seventh Edition. London: Pearson.2009.

[18] Sargent DJ, Hodges JS. Smoothed ANOVA with Application to Subgroup Analysis. Technical Report. Department of Biostatistics, University of Minnesota.

[19] Robinson GK. That BLUP is Good Thing: the Estimation of Random Effects. Statistical Science. 1991; 6:15-51. 